\title{
Differential generalization of habituation across contexts as a function of stimulus significance
}

\author{
JOHN G. M. EVANS \\ Monash University, Clayton, Victoria, Australia \\ and \\ GEOFFREY R. HAMMOND \\ University of Western Australia, Nedlands, Western Australia, Australia
}

\begin{abstract}
Orienting to one of two levels of stimulus significance (a distress squeal or a simulated mimic squeal) in female hooded rats was measured by suppression of ongoing drinking. Subsequent generalization tests with the same stimulus presented in different contexts showed that generalization of habituation across contexts was a function of stimulus significance: Habituation to the distress squeal was restricted to the context in which it first had been presented, whereas habituation to the mimic squeal generalized across the different contexts.
\end{abstract}

Apparently conflicting reports about the amount of transfer of habituation from one context to another have come from a wide variety of experimental situations. Some studies have indicated that habituation generalizes completely across contexts (e.g., Anderson, Wolf, \& Sullivan, 1969; Leaton, 1974; Leaton \& Jordan, 1978; Marlin \& Miller, 1981), whereas others have demonstrated that transfer is a function of contextual similarity-the greater the similarity, the greater the generalization (e.g., Falls \& Brooks, 1975; Montgomery, 1953; Peeke \& Veno, 1973). There have also been reports that transfer from one context to another does not occur (e.g., Mertl, 1977; Shalter, 1975; Shalter, Fentress, \& Young, 1977). However, because "context"' refers to the general setting of the experiment, and because any alteration in the internal or external environments constitutes a contextual change, differing results are perhaps not surprising. Nevertheless, despite the broadness of definition, there seems to be a pattern underlying the findings.

Although the studies that found complete generalization from one context to another all used rats as subjects, tones or buzzers as stimuli, and highly structured experimental environments, the degree to which the context was altered between training and testing varied considerably. Anderson et al. (1969) changed the entire apparatus from a holding cage to an operant chamber; Leaton (1974), in one experiment (Experiment 2), altered both the texture of

Send reprint requests to Geoffrey $\mathbf{R}$. Hammond, Department of Psychology, University of Western Australia, Nedlands, Western Australia 6009, Australia. the apparatus floor from sheet metal to a grid and the level of illumination from dark to light, whereas in another experiment (Experiment 3), he changed the motivational conditions from "thirsty but not drinking" to "thirsty and drinking." Perhaps the greatest contextual change occurred in Leaton and Jordan's (1978) demonstration that habituation of EEG arousal transferred completely from the waking to the sleeping state.

In contrast with the experiments outlined above, the reports of generalization's being a function of contextual similarity have come from studies in which more natural stimuli have been used. After measuring exploration by rats in black, gray, and white $\mathrm{H}$ mazes, Montgomery (1953) concluded that "the decrement in exploratory behavior produced by exposure to one stimulus situation generalizes to other situations, decreasing in magnitude as the similarity of the stimulus situation decreases" (p. 133). Peeke and Veno (1973) habituated sticklebacks to a male conspecific in a clear glass tube and then altered the location of the tube, changed the fish in the tube to a different conspecific male, or did both. The greatest transfer was observed when only the location was altered, less generalization occurred when the conspecific was changed but the location remained the same, and there was no transfer when both the location and the conspecific were changed. Falls and Brooks (1975) demonstrated that although whitethroated sparrows responded less strongly to a tape recording of a neighbor's song than of a stranger's song when the loudspeaker was near the neighbor's territory or in the center of the subject's territory, responding to the neighbor's song was greater when 
the song originated from the center of the subject's territory than when it came from near the correct boundary. Furthermore, when the loudspeaker was on the boundary farthest from the neighbor's territory, there was no difference in responsivity to the neighbor's and the stranger's songs.

Similarly, the studies that found no transfer of habituation from one context to another involved the use of natural stimuli. For example, Shalter (1975) habituated chickens to either a conspecific's warning call or a dark shape that passed overhead; he found that when the stimuli came from a different direction, responding returned to the original level. Shalter et al. (1977) habituated wolves to howls and found that when the context was altered by the introduction of a human lying down or a dog being held just outside the wolve's cages, or by the placing of mice in a transparent container in the cages, the responding returned to its original level. Mertl (1977) reported that lemurs that had habituated to scent markings on branches in a forest reserve did not generalize this habituation to a new location when the branches were shifted as little as $0.6 \mathrm{~m}$.

When the findings of the experiments described briefly above are looked at only in terms of the degree of contextual change, some counterintuitive results emerge: When the change in the physical environment was greater (e.g., from a holding cage to an operant chamber), habituation generalized completely, and yet when the physical changes were small (e.g., when branches in a forest were moved $0.6 \mathrm{~m}$ ), there was no transfer, thus suggesting the improbable conclusion that the larger the change in the physical environment, the greater the degree of generalization. However, a more plausible interpretation emerges when the findings are viewed in terms of the stimuli used. It seems that when the stimuli that are habituated to are biologically unimportant (e.g., tones), habituation generalizes from one context to another, but when the stimuli appear to have intrinsic biological significance for the subject, habituation to those stimuli generalizes to the degree that the contexts resemble each other, if at all. To put it another way, the generalization gradient across contexts may be steeper for biologically significant stimuli than for arbitrary stimuli. The present experiment used lick suppression as a measure of orienting in rats to either a recorded distress squeal or a recorded electronic simulation of a distress squeal. Previous work had shown different behavior to these two stimuli. With both stimuli presented at $100 \mathrm{~dB}$, orienting to the distress squeal was more prolonged on the initial stimulus presentation and subsequently habituated more slowly (Evans \& Hammond, 1983). The results showed that generalization across contexts was more restricted with the distress squeal.

\section{METHOD}

\section{Subjects}

Eighty female hooded Long-Evans rats between 130 and 140 days of age at the time of testing were housed two per cage in a controlled environment. A 12-h:12-h light:dark cycle was imposed, and the temperature was restricted to the range $21^{\circ} \mathrm{C}$ to $23^{\circ} \mathrm{C}$. Although food was continually available to the animals throughout the study, access to water was restricted as described below.

\section{Apparatus}

The test boxes were made of either white or black polyvinyl chloride. Each box was rectangular $(15 \times 32 \mathrm{~cm})$, was $12 \mathrm{~cm}$ deep, and had a stainless steel ballspout attached to a water bottle at one end. The white boxes had fine-mesh lids and had pine wood shavings on the floor; the black boxes had chicken-wire lids and had sand on the floor. Thus, the cages differed in most aspects (color, white vs. black; olfactory cues, pine vs. sand; floor texture, course shavings vs. fine sand; and box lids, fine vs. coarse mesh) other than in their sizes and in the fact that they both had the same type of drinking spout. This spout passed through an electrical coil, and as the rat licked, a magnet attached to the ball deflected, creating a small voltage that was amplified and recorded with a Grass polygraph (Model 7B). A television camera mounted above the test cages were used to take videotape records of the animals' behavior.

The stimuli used were recordings of a rat squeal and a mimic squeal. The distress squeal was recorded from a young adult male rat being given an intraperitoneal injection. The squeal was recorded on a tape recorder, and a sonagram (Kay Sona-Graph 6061D) of the squeal was made to determine its duration $(5 \mathrm{sec})$ and component frequencies. It was broken into seven bursts of noise varying in duration from 150 to $600 \mathrm{msec}$, with interburst

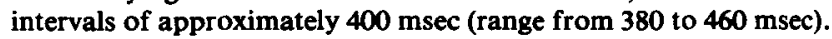
The major frequencies were around $2325,4347,6666,9000$, and $11,250 \mathrm{~Hz}$. With this information, a mimic squeal was constructed by simultaneously recording square waves (to obtain the harmonics apparent in the sonagram) of the above frequencies. These were generated by Exact function generators (Model 10383) and then spliced into a tape so that the temporal relationship of the bursts of sound in the squeal were reproduced. The nature of the recording and playback equipment restricted the frequency components of both stimuli to the range audible to humans.

The stimuli were replayed at $80 \mathrm{~dB}$ (SPL re: $0.0002 \mathrm{dynes} / \mathrm{cm}^{2}$, measured on a Kjaer Type $\mathbf{2 2 0 3}$ sound-level meter with the microphone placed at the drinking spout) to the animals during the experiment by a tape recorder through a loudspeaker $10 \mathrm{~cm}$ in front of and $40 \mathrm{~cm}$ above the drinking spout. As the stimulus was played, it was recorded simultaneously on both the videotape and the polygraph to record its temporal position in relation to the animal's behavior.

\section{Procedure}

Habituation was measured using the lick suppression technique (Zeiner \& Peeke, 1969). The rats were trained to lick at the spout, and while they were licking, the stimulus to be habituated to was presented. Total lick suppression due to orienting to the stimulus was measured on each trial. This measure was obtained by modifying the lick suppression recorded on the polygraph after viewing the videotape record. Thus, lick suppression not due to orienting (e.g., while the animals were grooming or digging) was identified and removed from the polygraph record, eliminating the need to use a suppression ratio to control for other than stimulus-induced lick suppression. Three categories of orienting were defined: (1) stationary orienting - the animal stopped drinking and looked up toward the speaker; (2) mobile orienting-the animal stopped drinking, looked up toward the speaker, and moved around the 
cage, constantly reorienting toward the speaker; (3) freezingthe animal initially oriented toward the speaker but then remained rigid in one position before either returning to drink or engaging in some other activity. In this way, both orienting durations and behavioral category judgments were obtained.

The animals were assigned randomly to one of six experimental or four comparison groups ( $n=8$ per group). The experimental groups represented one of two levels of stimulus significance, either the distress (D) or the mimic (M) squeal, and one of three levels of contextual change between the initial exposure session and the generalization test session: One group, the "same" (S) group, was exposed and tested in the white boxes; a second, the "familiar" (F) group, was exposed to the stimulus in the home cages and tested in the white boxes to which its rats had been familiarized; a third group, the "novel" (N) group, followed the same procedure as the $F$ group, with the exception that its rats had not been familiarized with the white test boxes. Thus, the groups were designated Groups DS (exposed to and tested with the distress squeal in the same place), MF (exposed to the mimic squeal in the home cage and tested with the mimic squeal in the white box with which they were familiar), and so on. The four comparison (C) groups were run to determine initial levels of orienting to the distress and mimic squeals in both familiar and novel environments. Thus, Group DFC was made up of those animals exposed to the distress squeal in a familiar environment. The remaining comparison groups were designated Groups MFC, DNC, and MNC.

Each animal was deprived of water in its home cage and was given two drinks per day, each of 15-min duration, at 2 and $10 \mathrm{~h}$ into the light cycle $(2 \mathrm{~h} \mathrm{~L}$ and $10 \mathrm{~h} \mathrm{~L})$ in either the white or the black test boxes, depending upon whether or not the white box was to be familiar or novel to them during the generalization test. Thus, the $S$ and $F$ groups had their drink training in the white boxes, and the $\mathbf{N}$ groups had theirs in the black boxes. On the 4th day, after the drink at $10 \mathrm{~h} \mathrm{~L}$, the animals in the experimental groups were given two presentations (spaced $3.5 \mathrm{~min}$ apart, offset to onset) of their designated stimulus, either in the white boxes with the spout removed (the $S$ groups) or in their home cages (the $F$ and $N$ groups). On the following day, the generalization test was given. The first drink was omitted and the drink at $10 \mathrm{~h} \mathrm{~L}$ was given to all animals in the white boxes. During this session, a stimulus was presented while the animals were drinking. For the animals in the experimental groups, this constituted a generalization trial, whereas for the animals in the comparison groups, it was their first exposure to the stimulus; this provided measures of the initial levels of orienting to the stimuli in both the familiar and the novel environments. videotape records of behavior were made during this session.

\section{RESULTS}

Figure 1 shows the median orienting duration to the generalization test stimulus types at each of the three levels of contextual change. Overall, the distress squeal was oriented to for longer than the mimic squeal $(U=4, p<.001)$; orienting duration increased as a function of amount of contextual change $[\mathrm{H}(2)$ $=11.26, p<.01]$; and orienting to the distress squeal increased more rapidly with contextual change than did orienting to the mimic squeal (stimulus type $X$ testing environment interaction, $\mathrm{H}(2)=8.54$, $\mathrm{p}<$ .02). These differences in orienting duration during the generalization test contrast with the behavior of the comparison groups on their first exposure to the stimulus, in which no differences as a function of either stimulus type (distress vs. mimic) or testing environment (novel vs. familiar) were evident. Median ori-

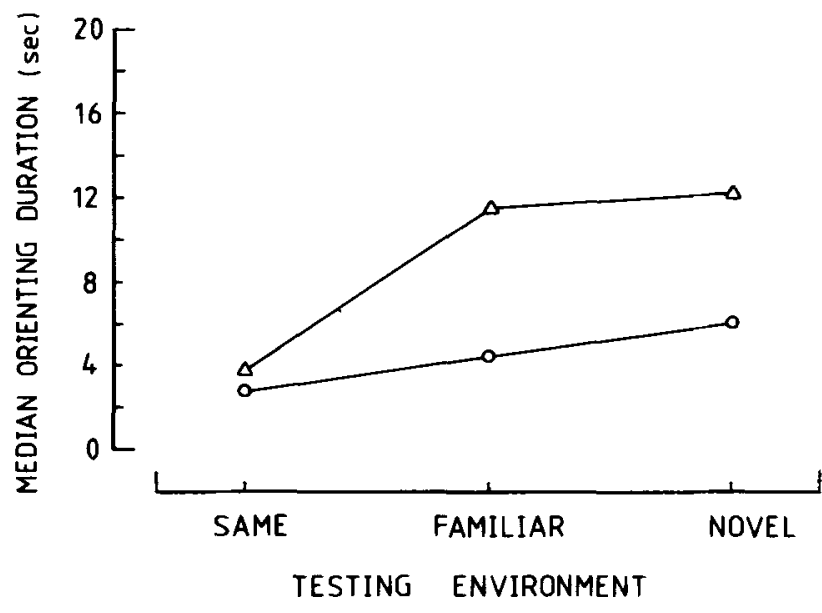

Figure 1. Median orienting duration to ench stimulus in each test condition (distress squeals, triangles; mimic squeals, circles).

enting durations (in seconds) for the comparison groups were as follows: MFC, 11.7; MNC, 9.1; DFC, 16.6; and DNC, 8.9. None of the statistical contrasts was significant. The category-judgment results paralleled the orienting-duration results: There was no statistical difference between the distributions of response types to the distress and mimic squeals on the generalization test in the "same" environmental condition ( $p>.05$, Fisher exact test); over contextual changes, more subjects mobile-oriented to the distress squeal than to the mimic squeal $\left[\chi^{2}(1)=8.17\right.$, $\mathrm{p}<.01]$; and more subjects mobile-oriented to the distress squeal than to the mimic squeal in the "familiar"' environment (8 vs. $4 ; p<.05$, Fisher exact test). The subjects not only oriented for longer to the distress squeals than to the mimic squeals in the changed environmental conditions, but also the nature of the orienting behavior was different.

\section{DISCUSSION}

These results show that generalization of habituation to a particular stimulus is a function of the biological significance of the stimulus; the generalization gradient for a biologically important stimulus is steeper than the generalization gradient for a biologically unimportant stimulus. This conclusion is restricted in that generalization was assessed on only one test trial, and it may be that although generalization is not evident on the first trial, it may emerge as savings in the number of exposures necessary for rehabituation. Since habituation in the type of procedure used here is typically complete with two or three stimulus exposures, such savings would be difficult to show. This demonstration might resolve the apparent discrepancy between the results of the experiments described in the introduction. It is not clear whether the differential generalization resulted 
from the different intrinsic significance of the stimuli or from the differential history of exposure to the two stimuli.' Although it seems unlikely that longterm preexposure to the mimic squeal would restrict generalization of habituation to it across contexts, the question can be answered only by experiment.

Orienting to a releasing stimulus does not appear to habituate completely (e.g., Melzack, 1961), and more rapid recovery of orienting over time to a distress squeal than to a mimic squeal has been reported (Evans \& Hammond, 1983). Along with these factors, more restricted generalization of habituation to a distress squeal may form a behavioral mechanism that acts to preserve orienting to important stimuli. Limited generalization of habituation across contexts may not be restricted to stimuli with intrinsic importance but may also apply with stimuli that have acquired significance through prior learning. Dexter and Merrill (1969) showed that habituation to the sound of a buzzer that was used subsequently as the conditioned stimulus in fear conditioning attenuated conditioned suppression only in the same test environment in which the stimulus had been presented initially.

These results also bear upon Wagner's (1976) shortterm-memory priming theory of habituation as a consequence of representation of the stimulus in short-term memory. This representation can be achieved in two ways, either by direct stimulus presentation or by retrieval from long-term memory. Since retrieval from long-term memory is triggered by other cues with which the stimulus has been associated, such as contextual cues, habituation should be context specific. The present results show this expectation to be too limited: Whether habituation is context specific or not depends upon the nature of the stimulus.

\section{REFERENCES}

Anderson, D. D., Wolf, D., \& Sullivan, P. Preconditioning exposures to the CS: Variation in place of testing. Psychonomic Science, 1969, 14, 233-235.

Dexter, W. R., \& MErrill, H. K. Role of contextual discrimination in fear conditioning. Journal of Comparative and Physiological Psychology, 1969, 69, 677-681.
Evans, J. G. M., \& Hammond, G. R. Habituation and tecovery of orienting in rats as a function of stimulus significance. Animal Learning \& Behavior, 1983, 11, 424-430.

FAlls, J. B., \& Brooks, R. J. Individual recognition by song in white-throated sparrows. II. Effects of location. Canadian Journal of Zoology, 1975, 53, 1412-1420.

LEATON, R. N. Long-term retention of the habituation of lick suppression in rats. Journal of Comparative and Physiological Psychology, 1974, 87, 1157-1164.

Leaton, R. N., \& Jondan, W. P. Habituation of the EEG arousal response in rats: Short- and long-term effects, frequency specificity, and wake-sleep transfer. Journal of Comparative and Physiological Psychology, 1978, 92, 803-814.

Marlin, N. A., \& Miller, R. R. Association to contextual stimuli as a determinant of long-term habituation. Journal of Experimental Psychology: Animal Behavior Processes, 1981, 7, 313-333.

Metzack, R. On the survival of mallard ducks after "habituation" to the hawk-shaped figure. Behaviour, 1961, 17, 9-16.

Mentr, A. S. Habituation to territorial scent marks in the field by Lemur cata. Behavioral Biology, 1977, 21, 500-507.

MontGomery, K. C. Exploratory behavior as a function of "similarity" of stimulus situations. Journal of Comparative and Physiological Psychology, 1953, 46, 129-133.

Peeke, H. V. S., \& VENo, G. Stimulus specificity of habituated aggression in three-spined sticklebacks (Gasterosteus aculeatus). Behavioral Biology, 1973, 8, 427-432.

Shalter, M. D. Lack of spatial generalization in habituation tests of fowl. Journal of Comparative and Physiological Psychology, 1975, 89, 258-262.

Shalter, M. D., Fentress, J. C., \& Youna, G. W. Determinants of response of wolf pups to auditory signals. Behavior, $1977,60,90-113$.

Whaven, A. R. Priming in short-term memory: An information processing model of retrieval generated depression in performance. In T. J. Tighe \& R. N. Leaton (Eds.), Habituation: Perspectives from child development, animal behavior and neurophysiology. New York: Wiley, 1976.

Zeiner, A. R., \& PeEKe, H. V. S. Habituation of response to distress cries in the rat: Measurement by an innate suppression technique. Communications in Behavioral Biology, 1969, 3, 249-252.

\section{NOTE}

1. We are grateful to a reviewer of an earlier version of this paper for raising this point and for bringing the work of Dexter and Merrill (1969) to our attention.

(Manuscript received February 11, 1983; revision accepted for publication June 10,1983 .) 